\title{
Chromosome 1p and 19q evaluation in low-grade oligodendrogliomas: A descriptive study
}

\author{
CHIARA MOLINARI ${ }^{1}$, PAOLO IORIO ${ }^{2,3}$, LAURA MEDRI $^{4}$, MICHELA BALLARDINI $^{*}$, \\ GRAZIANO GUIDUCCI ${ }^{2,5}$, ANNA MARIA CREMONINI ${ }^{2,5}$, SERENELLA CERASOLI ${ }^{2,6}$, \\ LUCA RICCIONI $^{2,6}$, MARINA FAEDI ${ }^{2,7}$, GIULIA ADALGISA MARIANI ${ }^{8}$, \\ WAINER ZOLI ${ }^{1}$, ROSELLA SILVESTRINI $^{1}$ and DANIELE CALISTRI ${ }^{1}$
${ }^{1}$ Istituto Scientifico Romagnolo per lo Studio e la Cura dei Tumori (I.R.S.T.), Meldola; ${ }^{2}$ Gruppo Neuroncologico Romagnolo (GNR), Cesena; ${ }^{3}$ Department of Clinical Pathology, Bufalini Hospital, Cesena; ${ }^{4}$ Pathology Unit, Morgagni-Pierantoni Hospital, Forlì; ${ }^{5}$ Neurosurgery, ${ }^{6}$ Pathology, and ${ }^{7}$ Oncology Units, Bufalini Hospital, Cesena; ${ }^{8}$ Department of Anatomical Sciences, University of Bologna, Bologna, Italy

Received July 30, 2009; Accepted September 15, 2009

DOI: 10.3892/ijmm_00000324

\begin{abstract}
Oligodendrogliomas are rare primary brain tumors with variable patient outcomes which are not always adequately accounted for by clinical or pathological variables. The present study evaluated the prognostic implications of chromosome $1 \mathrm{p}$ and $19 \mathrm{q}$ status in a set of 23 low grade oligodendrogliomas (OGD II), and correlated the results with patient outcome. Loss of heterozygosity $(\mathrm{LOH})$ and fluorescent in situ hybridization (FISH) analyses, the most widely used standard procedures, were used. $1 \mathrm{p}$ and $19 \mathrm{q}$ deletions were found in 65 and $61 \%$ of cases, respectively, using FISH and in 78 and $72 \%$ of cases using LOH. Both deletions were found in 56 and $64 \%$ of patients using FISH and LOH, respectively. Concordance between the results from the two techniques, determined by the Kappa statistics, ranged from fair to substantial depending on whether single or combined deletions were considered. Our results showed that the molecular alterations are associated with age and tumor localization. With regard to the impact of chromosomal alterations on clinical outcome, chromosome 19q deletions detected by LOH would seem to indicate a subgroup of patients at a higher risk of relapse, although the small number of patients recruited does not permit any definitive conclusions to be drawn. Further studies are now ongoing to determine whether this
\end{abstract}

Correspondence to: Dr Daniele Calistri, Istituto Scientifico Romagnolo per lo Studio e la Cura dei Tumori, Via Piero Maroncelli 40, 47014 Meldola (FC), Italy

E-mail: d.calistri@irst.emr.it

*Deceased

Key words: low grade oligodendroglioma, fluorescent in situ hybridization, loss of heterozygosity, $1 \mathrm{p}$ deletion, $19 \mathrm{q}$ deletion, clinical outcome methodological approach could be potentially useful in low grade oligodendrogliomas to better characterize chromosomal alterations of $1 \mathrm{p} / 19 \mathrm{q}$ and identify subgroups of patients with a higher risk of disease recurrence.

\section{Introduction}

Gliomas are the most frequent primary brain tumors in adults. Oligodendrogliomas (ODG) represent the second most common primary parenchymal brain tumors after astrocytomas and glioblastomas (1). The histological distinction between ODGs and astrocytomas is often difficult, and immunohistochemical analysis does not provide useful information for a differential diagnosis.

In the recent World Health Organization (WHO) Histopathological Classification, ODGs were defined as diffusely infiltrating grade II or III gliomas $(2,3)$. These tumors are known to be associated with different molecular genetic aberrations with respect to those observed in astrocytomas $(4,5)$. In particular, loss of heterozygosity $(\mathrm{LOH})$ at chromosome arms $1 \mathrm{p}$ and $19 \mathrm{q}$ has been detected, usually concomitantly, in a high percentage of oligodendrogliomas $(6,7)$, whereas it has seldom been found in astrocytic tumors (8). Moreover, copy number variations in genomic sequences, both at the chromosomal and subchromosomal levels, are currently under evaluation as potential cytogenetic markers of tumor aggressiveness (9). Prospective controlled clinical trials have shown that the presence of alterations in $1 p$ and $19 q$ detected by $\mathrm{LOH}$ assay is a favorable prognostic marker in both anaplastic oligodendrogliomas and oligoastrocytomas $(10,11)$. In particular, the concomitant presence of $\mathrm{LOH}$ in $1 \mathrm{p}$ and $19 q$ chromosome arms or in $1 p$ alone has been proposed as a potential indicator of responsiveness to chemotherapy and of prolonged survival in anaplastic oligodendroglioma patients $(4,11,12)$. Although the same alterations have also been reported to be correlated with prolonged overall survival in grade II oligodendrogliomas (ODG II) (13-15), this was not confirmed in a recent study based on multiplex ligationdependent probe amplification analysis (16). 
The correct management of patients with ODG II remains, therefore, an important problem. In fact, overall survival of ODG II patients is highly variable and unpredictable, making it difficult but also vital to find effective therapeutic options for postsurgical treatment (16-18).

In the present study we aimed to provide further information on the relevance of genetic alterations in predicting clinical outcome of ODG II by focusing on $1 \mathrm{p} / 19 \mathrm{q}$ deletions. Moreover, as the most widely used methodologies, fluorescent in situ hybridization (FISH) and loss of heterozygosity ( $\mathrm{LOH}$ ), do not always confer consistent results, we analyzed the genetic alterations using the two technical approaches, in parallel, on the same series of tumors.

\section{Materials and methods}

Case series. The current study was based on a retrospective review of 23 patients initially diagnosed with oligodendrogliomas and consecutively enrolled by the Gruppo Neuroncologico Romagnolo (GNR), a multidisciplinary medical association based in east-central Italy. Eleven patients were males and 12 females. Median age at the time of diagnosis was 40 years (range 28-70 years). The Karnofsky Performance Status (KPS) of patients at diagnosis was 100 for 19 patients, 80 for 2 patients and 70 for the remaining 2 patients.

All tumors were low grade oligodendrogliomas, according to World Health Organization guidelines (2). Hematoxylin and eosin-stained slides of all cases were reviewed by two independent neuropathologists. Lesion localization was frontal in 13 patients, temporal in 1 patient, and parietal in 1 patient, while the remaining 7 patients had disease involvement in more than one lobe, predominantly the temporal one.

After neuroradiological evaluation by the GNR team, all patients underwent surgery with intent to achieve the maximum safe resection. The extent of tumor removal was based on intraoperative and neuroimaging evaluations. Radical maximum safe resection was defined as $\geq 95 \%$ tumor burden reduction. Fifteen $(65 \%)$ patients underwent tumor mass reduction $\geq 95 \%, 7$ patients $(31 \%)$ had partial resection and 1 patient (4\%) underwent only stereotactic biopsy. After radical resection, follow-up consisted of clinical and imaging examinations every 6 months. For the patients submitted to partial resection, post-surgical treatment was individually prescribed. A radiotherapy schedule consisting of $60 \mathrm{~Gy}$ delivered in 1.8-2 Gy subfractions for 30-33 cycles with a 6 -week interval was the most frequent option. KPS evaluation was repeated after surgical treatment and every 6 months during follow-up. The median follow-up was 57 months (range 14-132).

Fluorescent in situ hybridization (FISH). FISH was performed on formalin-fixed paraffin-embedded tissues, as previously described (19). Briefly, deparaffinized sections were incubated in $0.2 \mathrm{M} \mathrm{HCl}$ for $20 \mathrm{~min}$ at room temperature. After a first wash in deionized water for $3 \mathrm{~min}$, samples were processed with the Paraffin Pre-treatment Kit (Vysis, Downers Grove, IL), washed in wash buffer for $3 \mathrm{~min}$, incubated in the Pretreatment Reagent (1 M Na SCN) for $30 \mathrm{~min}$ at $80^{\circ} \mathrm{C}$, rinsed in deioinized water for 1 min and again washed twice in wash buffer for $5 \mathrm{~min}$.

Samples were then incubated in a solution of $0.2 \mathrm{M} \mathrm{HCl} /$ $4 \mathrm{mg} / \mathrm{ml}$ protease at $37^{\circ} \mathrm{C}$ for $25 \mathrm{~min}$, rinsed twice in wash buffer for $5 \mathrm{~min}$, incubated in neutral buffered formalin for $10 \mathrm{~min}$, rinsed twice in wash buffer for $5 \mathrm{~min}$, and dehydrated. Ten microliters of probes was added to each slide, which were subsequently coverslipped, sealed and submitted to codenaturation $\left(85^{\circ} \mathrm{C}\right.$ for $\left.5 \mathrm{~min}\right)$ and hybridization $\left(37^{\circ} \mathrm{C}\right.$ for $18 \mathrm{~h}$, in a humid atmosphere) in a Hybrite (Vysis).

Nick-translated bacterial artificial chromosome (BAC) contiguous probes (Vysis) were used: the target region for chromosome 1 was at 1p36 (Spectrum Orange) with a control region at 1q25 (Spectrum Green), while the control region for chromosome 19 was at $19 \mathrm{p} 13$ (Spectrum Green) with the target region at 19q13 (Spectrum Orange).

After $18 \mathrm{~h}$, slides were incubated in a solution of $2 \mathrm{X}$ SSC $/ 0.3 \%$ Nonidet P-40 at room temperature for 2 min and then at $73^{\circ} \mathrm{C}$ for $2 \mathrm{~min}$, dried in a dark place and counterstained with $10 \mu \mathrm{l}$ of $0.2 \mu \mathrm{M} 4,6$ diamidino-2-phenylindole (DAPI) in antifade solution (Vysis). Tumor representativity was verified by staining sections adjacent to those submitted to FISH analysis with hematoxylin and eosin.

A Zeiss (Thornwood, NY) Axioplan microscope equipped with a triple-pass filter (DAPI/Green/Orange; Vysis) was used, and 200 nonoverlapping nuclei were scored. The specimen was considered deleted if the orange/green ratio was $\leq 0.80$ or, with a range between 0.81 and 0.85 , when the number of nuclei with a deletion of $1 \mathrm{p} 36$ or $19 \mathrm{q} 13$ orange signals was $>50 \%$.

Analysis of loss of heterozygosity. Tumor tissues were microdissected using the laser-assisted SL $\mu$ cut Microtest (MMI GmbH, Eching, Germany). The microdissected cells were placed on SL $\mu$ cut Transfer Film (Nikon, Florence, Italy) and digested overnight in a water bath at $55^{\circ} \mathrm{C}$ in $200 \mu 1$ of tissue lysis buffer (ATL, QIAamp ${ }^{\circledR}$ DNA Micro Kit; Qiagen GmbH, Hilden, Germany) containing $20 \mu \mathrm{l}$ of proteinase $\mathrm{K}$ provided by the same supplier. A carrier tRNA from Saccaromyces cerevisiae (Invitrogen, Milan, Italy) was added to the sample to improve DNA affinity for the subsequent isolation by Qiagen Spin Column (QIAamp DNA Micro Kit). Finally, DNA was eluted in $20 \mu 1$ of ultrapure distilled water (DNase, RNase Free, Invitrogen) and immediately processed for polymerase chain reaction (PCR). DNA samples were analyzed with different microsatellite markers, including D1S468 at 1p36.32, D1S214 at 1p36.31p36.23, D1S2736 at 1p36.22, D1S224 at 1p31.1, D1S514 at 1p12, D19S408 at 19q13.2, D19S867 at 19q13.33 and D19S926 at 19q13.4.

PCR primer sets for specific allele loci (MWG-Biotech, Ebersberg, Germany) were selected as described previously (20). Briefly, genomic DNA was amplified using PCR in a $25-\mu 1$ reaction volume containing $10 \mathrm{mmol} / 1$ Tris- $\mathrm{HCl}$ (pH 8.3), $10 \mathrm{mmol} / \mathrm{l} \mathrm{KCl}, 2.0 \mathrm{mmol} / 1 \mathrm{MgCl}_{2}, 200 \mathrm{~mol} / \mathrm{l}$ deoxynucleotide-triphosphates, $0.2 \mu \mathrm{mol} / 1$ forward 5'-Cy5 labeled primer, $0.20 \mu \mathrm{mol} / 1$ reverse primer, $1 \mathrm{X}$ GC rich solution (Roche Applied Science, Mannheim, Germany) and 1.25 U of FastStart Taq DNA polymerase (Roche Applied Science). PCR cycles consisted of $4 \mathrm{~min}$ at $95^{\circ} \mathrm{C}$ to 

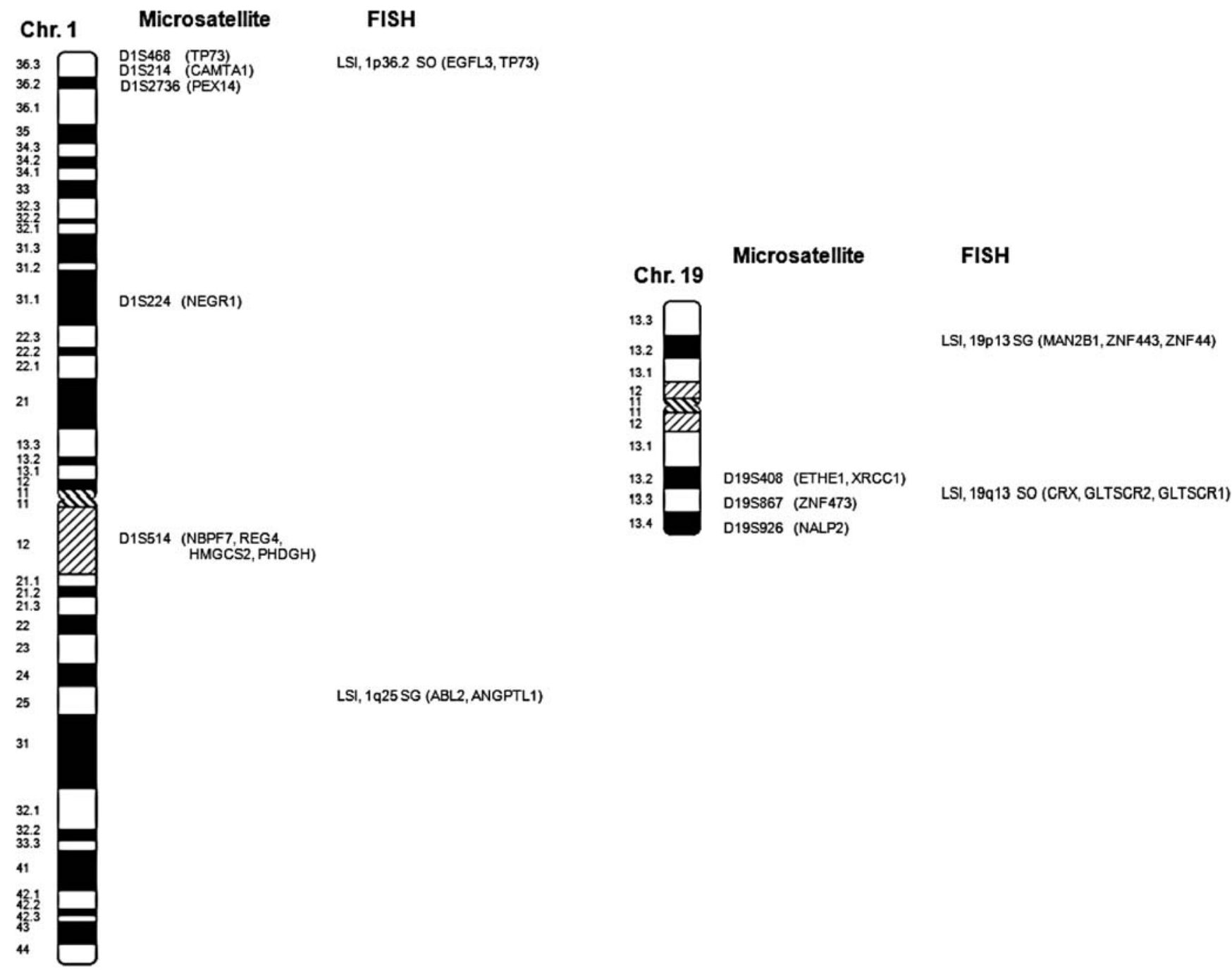

Figure 1. Chromosomal localization of microsatellite loci and FISH probes. The genes most closely related to single molecular markers are indicated in parentheses.

activate the enzyme, $30 \mathrm{sec}$ at $95^{\circ} \mathrm{C}, 30 \mathrm{sec}$ at $51^{\circ} \mathrm{C}$ for D19S867 and D1S468 or $55^{\circ} \mathrm{C}$ for the remaining markers, and $30 \mathrm{sec}$ at $72^{\circ} \mathrm{C}$, for a total of 40 cycles in an MJ PTC-100 Thermal Cycler (MJ Research, Watertown, MA).

One microliter of PCR products was diluted in $40 \mu \mathrm{l}$ of deionized formamide in the presence of a 600-bp D2-labeled ladder and loaded on a CEQ 2000 XL automatic DNA sequencer (Beckman Coulter, Fullerton, CA).

Allelic status in tumor DNA was evaluated using blood DNA from the same patient as reference. Allelic loss was considered positive at heterozygous loci in the presence of an imbalance of allele intensities $>25 \%$ (21). Tumor samples were classified as affected by $1 \mathrm{p}$ and/or $19 \mathrm{q} \mathrm{LOH}$ when at least one informative microsatellite marker under investigation was positive.

Statistical analysis. Statistical analyses were carried out with SPSS software (SPSS Inc, Chicago, IL) and the R statistical system (22). A Chi-square or Fisher exact test was performed to determine the association between patient characteristics and $1 \mathrm{p} / 19 \mathrm{q}$ deletions. The correlation between FISH and LOH was analyzed by the Kappa statistics (23). Disease-free survival (DFS) was defined as the time from surgery to disease progression or the last follow-up examination. DFS curves were estimated by the Kaplan-Maier method (24).

\section{Results}

Chromosome alterations using FISH and LOH analyses. In the present case series, a $1 \mathrm{p}$ deletion was found in $65 \%$ of cases using FISH and in $78 \%$ of cases using the LOH approach. A $19 q$ deletion was observed in 61 and $72 \%$ of cases using FISH and LOH techniques, respectively. The concomitance of deletions was found in 56 and $64 \%$ of cases using FISH and $\mathrm{LOH}$, respectively. The concordance of results obtained with the two techniques and determined by the Kappa statistic ranged from 0.26 (95\% CI, -0.19-0.72) for chromosome $1 \mathrm{p}$ to 0.50 (95\% CI, 0.12-0.90) for chromosome 19q. Concordance between FISH and $\mathrm{LOH}$ for both deletions was 0.63 (95\% CI, 0.30-0.96).

As microsatellites and FISH probes are directed against loci located in different chromosomal regions (Fig. 1), we evaluated the alterations in contiguous regions in order to try to explain the disagreement in results produced by the 
Table I. Chromosome alterations in relation to clinicopathological factors.

\begin{tabular}{|c|c|c|c|c|c|c|}
\hline & \multicolumn{6}{|c|}{ Percentage of tumors with chromosome alterations } \\
\hline & \multicolumn{3}{|c|}{ FISH } & \multicolumn{3}{|c|}{$\mathrm{LOH}$} \\
\hline & $1 \mathrm{p}$ & $19 q$ & $1 p / 19 q$ & $1 \mathrm{p}$ & $19 \mathrm{q}$ & $1 p / 19 q$ \\
\hline \multicolumn{7}{|l|}{ Gender } \\
\hline Females & $58(7 / 12)$ & $50(6 / 12)$ & $50(6 / 12)$ & $83(10 / 12)$ & $67(8 / 12)$ & $58(7 / 12)$ \\
\hline Males & $73(8 / 11)$ & $73(8 / 11)$ & $64(7 / 11)$ & $73(8 / 11)$ & $80(8 / 10)$ & $70(7 / 10)$ \\
\hline P-value & 0.667 & 0.400 & 0.680 & 0.640 & 0.646 & 0.675 \\
\hline \multicolumn{7}{|l|}{ Age (years) } \\
\hline$<40$ & $54(6 / 11)$ & $36(4 / 11)$ & $36(4 / 11)$ & $64(7 / 11)$ & $50(5 / 10)$ & $30(3 / 10)$ \\
\hline$\geq 40$ & $75(9 / 12)$ & $83(10 / 12)$ & $75(9 / 12)$ & $92(11 / 12)$ & $92(11 / 12)$ & $92(11 / 12)$ \\
\hline P-value & 0.400 & 0.036 & 0.100 & 0.155 & 0.056 & 0.006 \\
\hline \multicolumn{7}{|l|}{ Tumor site } \\
\hline Temporal & $50(4 / 8)$ & $37(3 / 8)$ & $25(2 / 8)$ & $50(4 / 8)$ & $62(5 / 8)$ & $37(3 / 8)$ \\
\hline Frontal and others & $73(11 / 15)$ & $73(11 / 15)$ & $73(11 / 15)$ & $93(14 / 15)$ & $79(11 / 14)$ & $79(11 / 14)$ \\
\hline P-value & 0.371 & 0.179 & 0.039 & 0.033 & 0.624 & 0.081 \\
\hline
\end{tabular}

Bold, statistically significant.

two methods. In particular, we analyzed chromosome 1 FISH probe LSI 1p36.2 with microsatellites D1S468 and D1S214, and FISH probe 19q13 with microsatellites D19S408 and 19S867. However, the concordance did not improve (data not shown).

Chromosome alterations and clinicopathological parameters. Chromosome alterations detected by FISH and microsatellite approaches were analyzed as a function of patient age, gender and tumor location (Table I). No differences in chromosome alteration frequencies were observed between males and females. Conversely, a lower frequency of deletions in chromosome arm 1p, more marked in chromosome arm 19q and also observed for both deletions, was found in younger ( $<40$ years) than in older patients using either approach. Similarly, a lower frequency of deletions was observed in temporal lobe tumors than in tumors localized elsewhere. The differences were evident for all of the markers and in some groups, such as those pertaining to age and tumor location, reached statistical significance despite the low number of patients.

Chromosome alterations and clinical outcome. Disease-free survival (DFS) was analyzed as a function of $1 p$ and $19 q$ chromosome alterations detected by FISH or LOH approaches (Fig. 2). At a median follow-up of 57 months, 10 recurrences were observed. The small number of patients recruited in our study did not allow us to perform statistical tests. However, from a rough analysis of the DFS paired curves, no differences were evident for patients with normal or deleted chromosome $1 \mathrm{p}$, chromosome $19 \mathrm{q}$ or both when detected by FISH. Conversely, only $19 q$ alterations detected by LOH distinguished two subgroups of patients at a different risk with $83 \%$ DFS when chromosome $19 q$ did not present alterations compared with only $32 \%$ when alterations were present at the time of diagnosis

\section{Discussion}

Histological diagnosis and the pathological classification currently used for gliomas present various limits in terms of reproducibility and do not provide accurate predictive information on clinical outcome, thus often preventing the optimal management of individual patients. Prognosis is defined on the basis of histotype, but in the ODG II subgroup, characterized by a more favorable outcome with respect to other CNS tumors, outcome is frequently heterogeneous and largely unpredictable (25).

ODG II are rare, slow-growing tumors, and patients show long-term survival, even though most eventually relapse and progress. Although immediate postoperative treatment is generally administered to patients with anaplastic ODG, there is an increasing tendency to delay adjuvant therapy in ODG II patients until there is clinical evidence of disease progression (26). The identification of this latter subgroup at high risk of recurrence is therefore important to select the individuals whose therapy must not be delayed.

It is becoming clear that the availability of genetic profiles could overcome the limits of traditional histology, permitting us to identify more accurate prognostic and predictive molecular markers. In particular, it has been shown that specific genetic alterations of chromosome $1 p$ and $19 q$ are potentially useful for the diagnosis and prognosis of ODG tumors. Although several studies have been carried out in this area, the results are somewhat discordant, probably because of the different and often non-standardized methodological approaches used and the limited case series analyzed, due to the low incidence of ODG II. 


\section{FISH}

Chromosome 1

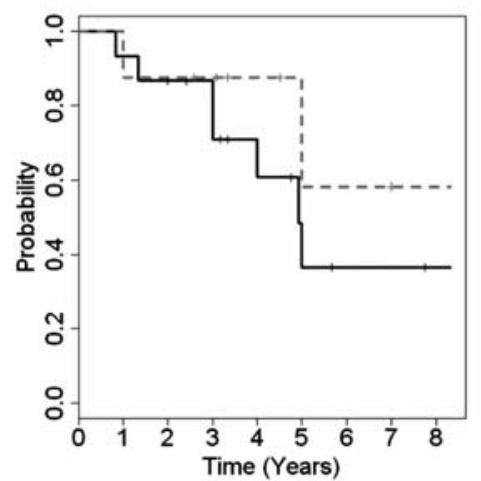

LOH

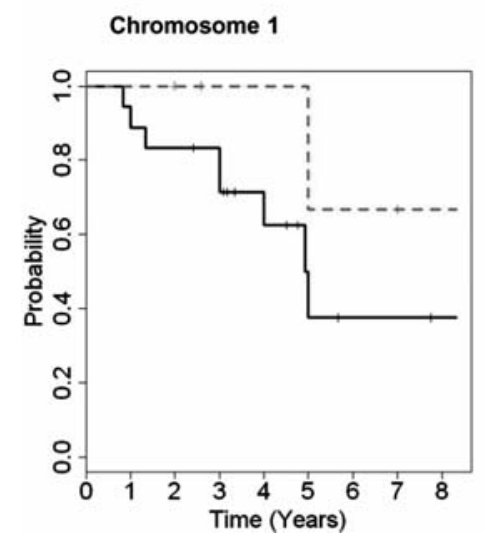

Chromosome 19

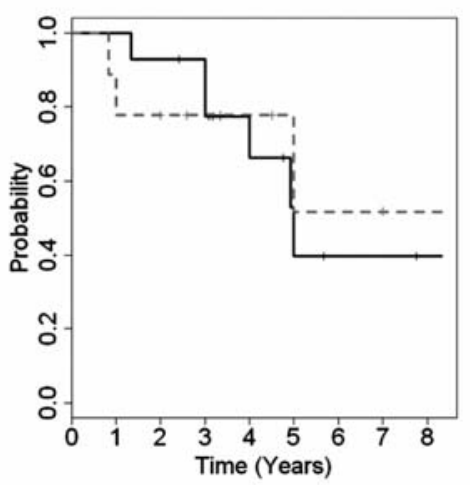

Chromosome 19

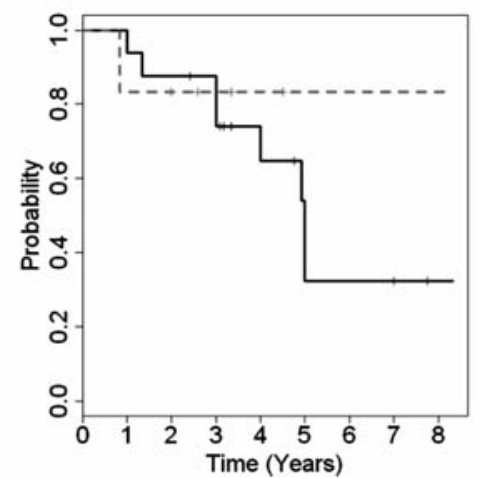

Chromosomes 1 and 19

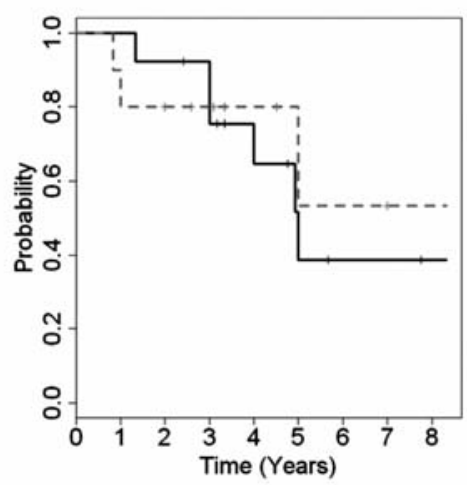

-... Normal - Delete

Figure 2. Disease-free survival as a function of $1 \mathrm{p}$ and $19 \mathrm{q}$ chromosome status according to different molecular approaches.

In an attempt to explore potential methodological bias and to identify the molecular features highlighted by the various available approaches, we analyzed, in parallel, fluorescent in situ hybridization and loss of heterozygosity on the same series of tumors. These are the two most frequently used techniques to analyze $1 p$ and $19 q$ status, which are known to be important targets in gliomas (27).

Although LOH analysis is relatively rapid and inexpensive, it has the disadvantage of requiring paired blood samples. In contrast, FISH, albeit more expensive, does not require normal cells from the same patient and can be performed with a lower number of cells than that needed for $\mathrm{LOH}$ analysis. Moreover, FISH offers the possibility of correlating alterations with morphology and immunocytology.

Our findings on the frequency of $1 p$ and $19 q$ deletions are in line with those published in the literature, and we also confirmed the previously reported prevalence of $1 \mathrm{p}$ deletions over $19 q$ alterations $(8,20,28,29)$. However, a detailed analysis of our LOH and FISH results shows that agreement between the two techniques ranged from fair to moderate for single alterations and was substantial only for the concomitance of deletions on $1 \mathrm{p}$ and $19 \mathrm{q}$ chromosomes. The partial discordance was mainly due to an underestimation by FISH. The use of different probes directed against different genomic regions could also be responsible for this partial discordance.
With regard to the relation between the presence of chromosome deletions and clinicopathological factors, Myal and coauthors, in their study on a heterogeneous case series of CNS tumors, reported a higher frequency of $1 \mathrm{p}$ and $19 \mathrm{q}$ deletions in younger than in older patients (30). However, a breakdown analysis that we carried out on Myal's ODG II subgroup highlighted an inverse situation, with data similar to those obtained in our study. In fact, the frequency of single and both deletions was always 2 - to 3 -fold lower in younger than in older patients, the difference reaching statistical significance in some cases. Moreover, the higher frequency of both $1 \mathrm{p}$ and $19 \mathrm{q}$ chromosomal losses observed in nontemporal tumors in a series of ODG $(31,32)$ was confirmed in our series of ODG II patients.

Analysis of the relation between clinical outcome and genetic signature was investigated in subsets of patients with ODG II belonging to mixed case series and submitted to various types of chemotherapy and radiotherapy $(27,33)$. Both studies reported a better clinical outcome in terms of progression-free and overall survival in patients with tumors harboring $1 \mathrm{p}$ and $19 \mathrm{q}$ deletions compared to patients with a normal genetic signature. However, the authors concluded that it is not clear whether specific $1 p / 19 q$ deletions are favorable prognostic markers or predictors of response to adjuvant treatment. 
Recently, Weller and co-authors showed that combined $1 \mathrm{p} / 19 \mathrm{q}$ loss is not a strong prognostic biomarker in patients with oligodendroglial tumors who do not receive radiotherapy or chemotherapy (16). For this reason, they hypothesized that the loss of $1 \mathrm{p} / 19 \mathrm{q}$ per se, in the absence of genotoxic treatment, might not confer a disease-free survival advantage, suggesting that the gene products lost in $1 \mathrm{p} / 19 \mathrm{q}$ co-deletion could be mediators of resistance to therapies. On the other hand, Megyesi et al showed that, in ODG treated by surgery only, there is a significant association between the presence of co-deletions $1 \mathrm{p} / 19 \mathrm{q}$ and indistinct tumor border on magnetic resonance imaging. This association indicates that $1 p / 19 q$ allelic loss could be indicative of an invasive phenotype (34).

In our study of only ODG II patients, a better prognosis was observed for those with normal genetic profiles who had not yet reached a median DFS at a follow-up of 8 years compared to the 5-year median DFS observed in patients who presented deletions in either chromosomes 1 or 19 , or in both. In particular, $1 \mathrm{p}$ losses detected by either FISH or LOH approaches did not identify subgroups at a different risk of recurrence. Conversely, LOH-detected deletions produced more diversified DFS curves, especially for chromosome 19 losses.

Finally, given the limited statistical power of this small case series, it is not possible to draw meaningful conclusions. Further studies on a larger number of patients are now needed in order to confirm our results.

\section{Acknowledgements}

The authors wish to thank Gráinne Tierney for editing the manuscript.

\section{References}

1. 2005-2006, Primary Brain Tumors in the United States Statistical Report, 1998-2002. Available from http://www cbtrus.org/reports//2005-2006/2006report.pdf.

2. Kleihues P and Sobin LH: World Health Organization Classification of Tumors. Cancer 88: 2887, 2000.

3. Louis DN: Molecular pathology of malignant gliomas. Annu Rev Pathol 1: 97-117, 2006.

4. Cairncross JG, Ueki K, Zlatescu MC, Jenkins R, Scheithauer B, Brachman D, Buckner J, Fink K, Souhami L, Laperierre N, Mehta M and Curran W: Specific genetic predictors of chemotherapeutic response and survival in patients with anaplastic oligodendrogliomas. J Natl Cancer Inst 90: 1473-1479, 1998.

5. Chinot O: Chemotherapy for the treatment of oligodendroglial tumors. Semin Oncol 28 (Suppl 13): 13-18, 2001.

6. Okamoto Y, Di Patre PL, Burkhard C, Horstmann S, Jourde B, Fahey M, Schüler D, Probst-Hensch NM, Yasargil MG, Yonekawa Y, Lütolf UM, Kleihues P and Ohgaki H: Populationbased study on incidence, survival rates, and genetic alterations of low-grade diffuse astrocytomas and oligodendrogliomas. Acta Neuropathol 108: 49-56, 2004.

7. Smith JS, Perry A, Borell TJ, Lee HK, O'Fallon J, Hosek SM, Kimmel D, Yates A, Burger PC, Scheithauer BW and Jenkins RB: Alterations of chromosome arms $1 \mathrm{p}$ and $19 \mathrm{q}$ as predictors of survival in oligodendrogliomas, astrocytomas, and mixed oligoastrocytomas. J Clin Oncol 18: 636-645, 2000.

8. Smith JS, Alderete B, Minn Y, Borell TJ, Perry A, Mohapatra G, Hosek SM, Kimmel D, O'Fallon J, Yates A, Feuerstein BG, Burger PC, Scheithauer BW and Jenkins RB: Localization of common deletion regions on $1 \mathrm{p}$ and $19 \mathrm{q}$ in human gliomas and their association with histological subtype. Oncogene 18: 4144-4152, 1999.
9. Dehais C, Laigle-Donadey F, Marie Y, Kujas M, Lejeune J, Benouaich-Amiel A, Pedretti M, Polivka M, Xuan KH, Thillet J, Delattre JY and Sanson M: Prognostic stratification of patients with anaplastic gliomas according to genetic profile. Cancer 107: 1891-1897, 2006.

10. Cairncross G, Berkey B, Shaw E, Jenkins R, Scheithauer B, Brachman D, Buckner J, Fink K, Souhami L, Laperierre N, Mehta M and Curran W: Phase III trial of chemotherapy plus radiotherapy compared with radiotherapy alone for pure and mixed anaplastic oligodendroglioma: Intergroup Radiation Therapy Oncology Group Trial 9402. J Clin Oncol 24: 2707-2714, 2006

11. Van den Bent MJ, Carpentier AF, Brandes AA, Sanson M, Taphoorn MJ, Bernsen HJ, Frenay M, Tijssen CC, Grisold W, Sipos L, Haaxma-Reiche H, Kros JM, van Kouwenhoven MC, Vecht CJ, Allgeier A, Lacombe D and Gorlia T: Adjuvant procarbazine, lomustine, and vincristine improves progressionfree survival but not overall survival in newly diagnosed anaplastic oligodendrogliomas and oligoastrocytomas: a randomized European Organisation for Research and Treatment of Cancer phase III trial. J Clin Oncol 24: 2715-2722, 2006.

12. Ino Y, Betensky RA, Zlatescu MC, Sasaki H, Macdonald DR, Stemmer-Rachamimov AO, Ramsay DA, Cairncross JG and Louis DN: Molecular subtypes of anaplastic oligodendroglioma: implications for patient management at diagnosis. Clin Cancer Res 7: 839-845, 2001.

13. Mariani L, Deiana G, Vassella E, Fathi AR, Murtin C, Arnold M, Vajtai I, Weis J, Siegenthaler P, Schobesberger M and Reinert MM: Loss of heterozygosity $1 \mathrm{p} 36$ and $19 \mathrm{q} 13$ is a prognostic factor for overall survival in patients with diffuse WHO grade 2 gliomas treated without chemotherapy. J Clin Oncol 24: 4758-4763, 2006.

14. Quinn JA, Reardon DA, Friedman AH, Rich JN, Sampson JH, Provenzale JM, McLendon RE, Gururangan S, Bigner DD, Herndon JE II, Avgeropoulos N, Finlay J, Tourt-Uhlig S, Affronti ML, Evans B, Stafford-Fox V, Zaknoen S and Friedman HS: Phase II trial of temozolomide in patients with progressive low-grade glioma. J Clin Oncol 21: 646-651, 2003.

15. Van den Bent MJ, Taphoorn MJ, Brandes AA, Menten J, Stupp R, Frenay M, Chinot O, Kros JM, van der Rijt CC, Vecht ChJ, Allgeier A, Gorlia T; European Organization for Research and Treatment of Cancer Brain Tumor Group: Phase II study of first-line chemotherapy with temozolomide in recurrent oligodendroglial tumors: the European Organization for Research and Treatment of Cancer Brain Tumor Group Study 26971. J Clin Oncol 21: 2525-2528, 2003.

16. Weller M, Berger H, Hartmann C, Schramm J, Westphal M, Simon M, Goldbrunner R, Krex D, Steinbach JP, Ostertag CB, Loeffler M, Pietsch T and von Deimling A: Combined 1p/19q loss in oligodendroglial tumors: predictive or prognostic biomarker? Clin Cancer Res 13: 6933-6937, 2007

17. Dehghani F, Schachenmayr W, Laun A and Korf HW: Prognostic implication of histopathological, immunohistochemical and clinical features of oligodendrogliomas: a study of 89 cases. Acta Neuropathol 95: 493-504, 1998

18. Olson JD, Riedel E and DeAngelis LM: Long-term outcome of low-grade oligodendroglioma and mixed glioma. Neurology 54 : $1442-1448,2000$

19. Press MF, Slamon DJ, Flom KJ, Park J, Zhou JY and Bernstein L: Evaluation of HER-2/neu gene amplification and overexpression: comparison of frequently used assay methods in a molecularly characterized cohort of breast cancer specimens. J Clin Oncol 20: 3095-3105, 2002.

20. Nigro JM, Takahashi MA, Ginzinger DG, Law M, Passe S, Jenkins RB and Aldape K: Detection of $1 \mathrm{p}$ and $19 \mathrm{q}$ loss in oligodendroglioma by quantitative microsatellite analysis, a real-time quantitative polymerase chain reaction assay. Am J Pathol 158: 1253-1262, 2001.

21. Devilee P, Cleton-Jansen AM and Cornelisse CJ: Ever since Knudson. Trend Genet 17: 569-573, 2001.

22. R Development Core Team: A language and environment for statistical computing, Vienna, Austria. ISBN 3-900051-07-0, URL http://www.R.project.org. Accessed 20 November, 2008.

23. Landis JR and Koch GG: The measurement of observer agreement for categorical data. Biometrics 33: 159-174, 1977.

24. Kaplan EL and Meier P: Non-parametric estimation from incomplete observation. J Am Stat Assoc 53: 457-481, 1958 
25. Giannini C, Burger PC, Berkey BA, Cairncross JG, Jenkins RB, Mehta M, Curran WJ and Aldape K: Anaplastic oligodendroglial tumors: refining the correlation among histopathology, 1p 19q deletion and clinical outcome in Intergroup Radiation Therapy Oncology Group Trial 9402. Brain Pathol 18: 360-369, 2008.

26. Mason WP: Oligodendroglioma. Curr Treat Options Neurol 7: 305-314, 2005

27. Iwamoto FM, Nicolardi L, Demopoulos A, Barbashina V Salazar P, Rosenblum M and Hormigo A: Clinical relevance of $1 \mathrm{p}$ and $19 \mathrm{q}$ deletion for patients with WHO grade 2 and 3 gliomas. J Neurooncol 88: 293-298, 2008.

28. Jeuken JW, von Deimling A and Wesseling P: Molecular pathogenesis of oligodendroglial tumors. J Neurooncol 70 : 161-181, 2004.

29. Reifenberger G and Louis DN: Oligodendroglioma: toward molecular definitions in diagnostic neuro-oncology. J Neuropathol Exp Neurol 62: 111-126, 2003.

30. Myal Y, Del Bigio MR and Rhodes RH: Age-related differences in $1 \mathrm{p}$ and $19 \mathrm{q}$ deletions in oligodendrogliomas. BMC Clin Pathol 3: 6, 2003.
31. Mueller W, Hartmann C, Hoffmann A, Lanksch W, Kiwit J, Tonn J, Veelken J, Schramm J, Weller M, Wiestler OD, Louis DN and von Deimling A: Genetic signature of oligoastrocytomas correlates with tumor location and denotes distinct molecular subsets. Am J Pathol 161: 313-319, 2002.

32. Zlatescu MC, TehraniYazdi A, Sasaki H, Megyesi JF, Betensky RA, Louis DN and Cairncross JG: Tumor location and growth pattern correlate with genetic signature in oligodendroglial neoplasms. Cancer Res 61: 6713-6715, 2001.

33. Jaeckle KA, Ballman KV, Jenkins RB and Buckner JC: Current strategies in treatment of oligodendroglioma: evolution of molecular signatures of response. J Clin Oncol 24: 1246-1252, 2006.

34. Megyesi JF, Kachur E, Lee DH, Zlatescu MC, Betensky RA, Forsyth PA, Okada Y, Sasaki H, Mizoguchi M, Louis DN and Cairncross JG: Imaging correlates of molecular signatures in oligodendrogliomas. Clin Cancer Res 10: 4303-4306, 2004. 